\title{
ANALISIS PERBANDINGAN HARGA JARINGAN LISTRIK PENERANGAN PADA MODEL JARINGAN KONVENSIONAL DAN JARINGAN BERBASIS RELE
}

\section{COMPARATIVE PRICING ANALYSIS OF LIGHTING ELECTRICAL NETWORK ON CONVENTIONAL NETWORK AND NETWORK BASED ON RELAY}

\author{
Efa Maydhona Saputra ${ }^{1}$, Diki Dirgiantara ${ }^{2}$, Topan Wira Buana ${ }^{3}$ \\ 1,2,3 Institut Teknologi Sumatera, Lampung Selatan
}

1'maydhona@el.itera.ac.id, ${ }^{2}$ diki.13116041@ student.itera.ac.id, ${ }^{3}$ topan.13117083@ student.itera.ac.id

\begin{abstract}
Abstrak
Jaringan listrik penerangan pada penelitian ini digunakan hanya untuk menyalakan dan mematikan lampu. Jaringan konvensional dan jaringan berbasis rele memiliki beberapa perbedaan, salah satunya jenis kabel yang digunakan. Jaringan konvensional menggunakan jenis kabel NYM, sedang jaringan berbasis rele menggunakan kabel UTP. Harga kabel UTP lebih rendah daripada kabel NYM.

Penelitian ini menganalisis perbandingan harga jaringan konvensional dan jaringan berbasis rele, dengan terlebih dahulu membuat purwarupa kedua jaringan. Kemudian dari purwarupa tersebut, dilakukan pengujian terhadap panjang maksimum kabel UTP untuk menentukan apakah jaringan berbasis rele layak diterapkan untuk bangunan besar. Kemudian, dari formula harga masing-masing jaringan, dicari sebuah formula untuk menentukan jaringan mana yang membutuhkan biaya lebih sedikit.

Hasil penelitian menunjukkan, purwarupa yang dibuat dapat bekerja dengan baik. Jaringan berbasis rele terbukti dapat diaplikasikan pada bangunan besar, karena kabel UTP yang digunakan dapat mencapai panjang 22900 meter. Panjang kabel $=L=\frac{\left(N \times R_{r p}\right)+(((N-1) \operatorname{div} 28)+1) \times\left(P_{r p}+S_{r p}\right)}{\left(2 \times E_{r p}-2 \times T_{r p}\right)}$ menjadi titik temu antara biaya jaringan konvensional dan jaringan berbasis rele. Bila panjang kabel lebih rendah dari L, biaya jaringan konvensional lebih rendah dari biaya jaringan berbasis rele. Dan bila panjang kabel lebih tinggi dari L, berlaku sebaliknya.
\end{abstract}

Kata kunci : harga, penerangan, jaringan listrik, konvensional, rele

\begin{abstract}
Electrical lighting network in this study is used only to turn the lights on and off. Conventional networks and relay based networks have several differences, one of them is the type of cable used. Conventional networks use NYM cable types, while relay-based networks use UTP cables. UTP cable price is lower than NYM cable.

This research analyzes comparison of conventional network price and relay based network, by firstly creating prototype of both network. Then from the prototype, we test the maximum length of UTP cable to determine whether the relay-based network is feasible to be applied to large buildings. Then, from the price formula of each network, a formula is sought to determine which networks cost less.

The results show, prototypes are made to work well. Relay-based networks are proven to be applicable to large buildings, because UTP cables used can reach lengths of 22900 meters.

Cable length $=L=\frac{\left(N \times R_{r p}\right)+(((N-1) \text { div } 28)+1) \times\left(P_{r p}+S_{r p}\right)}{\left(2 \times E_{r p}-2 \times T_{r p}\right)}$ became the meeting point between the cost of conventional networks and relay-based networks. When cable length is lower than $\mathrm{L}$, the cost of
\end{abstract}


conventional networks is lower than the cost of relay-based networks. And if the cable length is higher than L, apply otherwise.

\section{Keywords: price, lighting, electrical network, conventional, relay}

\section{PENDAHULUAN}

Model jaringan listrik untuk penerangan di gedung atau perumahan umumnya menerapkan jaringan listrik konvensional, yaitu menyambungkan jaringan listrik dengan saklar dan lampu. Bila jarak lampu dan saklar cukup jauh, biasanya teknisi listrik akan menarik kabel jenis NYM cukup panjang untuk menghubungkan saklar dan lampu. Pada kasus ini, faktor biaya biasanya diabaikan dan cenderung dianggap resiko karena teknisi tidak memiliki pilihan lain selain menarik kabel panjang.

Relay (rele) sebagai teknologi pengganti saklar, mampu menggantikan fungsi saklar dengan kontrol tegangan yang cukup rendah berkisar 3 sampai 5 Volt. T. Ahri Bahriun, staf pengajar Teknik Elektro USU dalam papernya menyatakan, sebuah rele dapat dikontrol dengan daya 2 5VA [1]. Artinya, dalam situasi lampu dan saklar cukup jauh, teknisi tidak perlu menarik kabel NYM, teknisi hanya perlu menarik kabel kecil yang harganya jauh lebih murah daripada kabel NYM, misalnya kabel unshielded twisted pair (UTP) yang bisa ditemukan pada kabel telpon atau kabel LAN.

Beberapa uraian di atas menunjukkan bahwa kita masih bisa mewujudkan jaringan listrik yang hemat biaya dengan memanfaatkan rele. Untuk dapat membandingkan kebutuhan biaya jaringan konvensional dan jaringan berbasis rele, pertama kami harus merancang dan merealisasikan prototype keduanya agar diketahui semua komponen pendukungnya. Kedua, memastikan jaringan berbasis rele ini dapat diaplikasikan pada bangunan berukuran besar, mengingat jaringan berbasis rele ini menggunakan jenis kabel yang memiliki hambatan cukup besar karena ukurannya yang kecil.

\section{TINJAUAN PUSTAKA}

\subsection{Jaringan Listrik [2]}

Selama ini, untuk membuat jaringan penerangan rumah, kita mengenal jaringan listrik konvensional yang memiliki diagram seperti digambarkan pada Gambar 1.

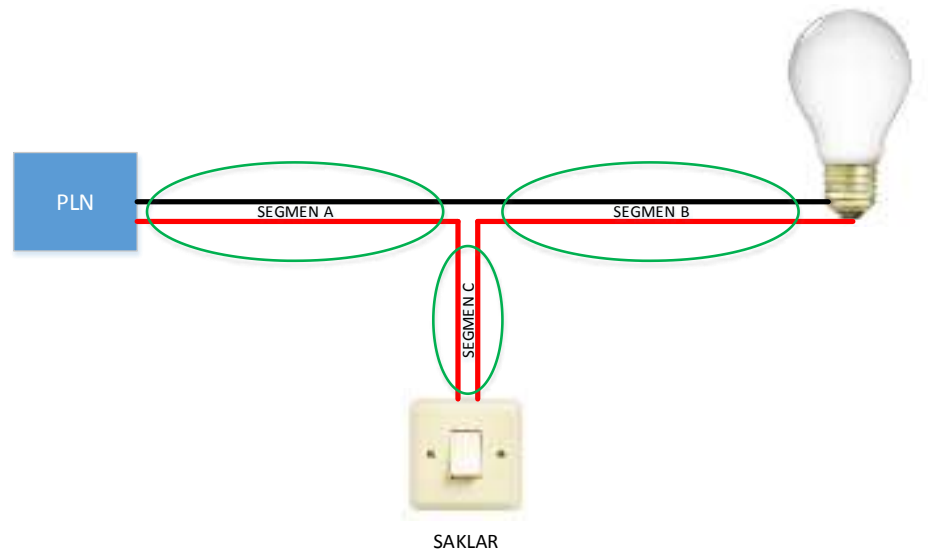

Gambar 1 Jaringan Listrik Penerangan Konvensional

Pada rangkaian tersebut, terdapat 3 segmen pengkabelan yang dapat dibedakan dengan mudah. Pada jaringan listrik konvensional, ketiga segmen kabel tersebut biasanya menggunakan 
kabel berjenis kabel NYM (biasa disebut sebagai kabel engkel). Pada penelitian ini, rangkaian di atas saya sebut sebagai Jaringan konvensional.

Pada penelitian ini, kami melakukan rekayasa pengkabelan untuk segmen $\mathrm{C}$ sehingga diagram jaringan listrik menjadi seperti pada Gambar 2 yang pada penelitian ini saya sebut sebagai Jaringan Berbasis Rele.

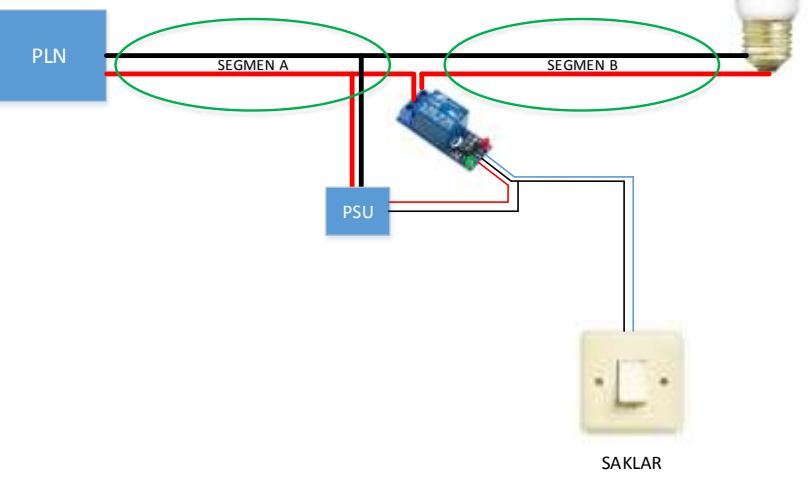

Gambar 2 Jaringan Listrik Penerangan Berbasis Rele

Perbedaan mendasar kedua jenis rangkaian tersebut adalah pada segmen C. Pada jaringan konvensional, segmen ini menggunakan kabel engkel. Sedangkan pada Jaringan berbasis rele, segmen ini digantikan dengan sebuah Relay, Power Supply, dan kabel UTP. Salah satu keunggulan dari jaringan berbasis rele ini adalah kita bisa menggunakan kabel UTP, yang harganya lebih murah, untuk menghubungkan saklar dengan rele. Penggunaan kabel UTP pada jaringan ini bukan sebagai kabel catu daya, melainkan hanya melewatkan logika 0 atau 1.

\subsection{Kabel Listrik untuk Penerangan (pencahayaan) [3]}

Penggunaan kabel untuk jaringan listrik diatur dalam Persyaratan Umum Instalasi Listrik (PUIL). Khusus untuk jaringan listrik penerangan (Pencahayaan), penggunaan kabel mengacu pada Tabel 1.

Tabel 1 Luas Penampang minimum konduktor [3]

\begin{tabular}{|c|c|c|c|c|}
\hline \multirow{2}{*}{\multicolumn{2}{|c|}{ Jenis Sistem Perkawatan }} & \multirow{2}{*}{ Penggunaan Sirkit } & \multicolumn{2}{|r|}{ Konduktor } \\
\hline & & & Bahan & Luas Penampang $\mathrm{mm}^{2}$ \\
\hline \multirow{4}{*}{$\begin{array}{l}\text { Instalasi } \\
\text { magun } \\
\text { (terpasang } \\
\text { tetap) }\end{array}$} & \multirow{2}{*}{$\begin{array}{l}\text { Kabel dan } \\
\text { konduktor } \\
\text { berinsulasi }\end{array}$} & Sirkit daya dan pencahayaan & $\begin{array}{l}\text { Tembaga } \\
\text { Aluminium }\end{array}$ & $\begin{array}{c}1.5 \\
2.5(\text { lihat Catatan } 1)\end{array}$ \\
\hline & & Sirkit sinyal dan kendali & Tembaga & 0.5 (lihat Catatan 2) \\
\hline & \multirow{2}{*}{$\begin{array}{l}\text { Konduktor } \\
\text { polos }\end{array}$} & Sirkit sinyal dan kendali & $\begin{array}{l}\text { Tembaga } \\
\text { Aluminium }\end{array}$ & $\begin{array}{l}10 \\
16\end{array}$ \\
\hline & & Sirkit sinyal dan kendali & Tembaga & 4 \\
\hline \multirow{3}{*}{\multicolumn{2}{|c|}{$\begin{array}{l}\text { Hubungan fleksibel } \\
\text { dengan konduktor } \\
\text { berinsulasi dan kabel }\end{array}$}} & Untuk peranti spesifik & \multirow{3}{*}{ Tembaga } & $\begin{array}{l}\text { Seperti ditentukan dalam } \\
\text { standar IEC yang relevan }\end{array}$ \\
\hline & & Untuk setiap penerapan lain & & $0.75^{*}$ \\
\hline & & $\begin{array}{l}\text { Sirkit voltase ekstra rendah } \\
\text { untuk penerapan khusus }\end{array}$ & & 0.75 \\
\hline \multicolumn{2}{|l|}{ Catatan 1} & \multicolumn{3}{|c|}{$\begin{array}{l}\text { Konektor yang digunakan untuk terminasi konduktor aluminium harus } \\
\text { diuji dan disahkan untuk penggunaan spesifik ini }\end{array}$} \\
\hline \multicolumn{2}{|l|}{ Catatan 2} & \multicolumn{3}{|c|}{$\begin{array}{l}\text { Pada sirkit sinyal dan kendali yang dimaksudkan untuk perlengkapan } \\
\text { elektronik, diizinkan menggunakan luas penampang minimum } 0.1 \mathrm{~mm}^{2}\end{array}$} \\
\hline \multicolumn{2}{|l|}{$*$} & \multicolumn{3}{|c|}{$\begin{array}{l}\text { Pada kabel fleksibel multiinti yang berisikan tujuh inti atau lebih, berlaku } \\
\text { Catatan 2. antar fase. }\end{array}$} \\
\hline
\end{tabular}


Dari tabel tersebut, pada penelitian ini, kami menggunakan kabel NYM $1.5 \mathrm{~mm}^{2}$ sebagai kabel konduktor berinsulasi dan kabel UTP dari kabel LAN untuk Kabel sinyal dan kendali. Sesuai dengan Catatan 2, Kabel LAN memiliki diameter sekitar $0.57 \mathrm{~mm}$ [4], yang berarti memiliki luas penampang sebesar $0.25 \mathrm{~mm}^{2}$.

\subsection{Rele (Relay) [5]}

Rele adalah Saklar yang dioperasikan secara listrik dan merupakan komponen electromechanical yang terdiri dari 2 bagian utama yakni Elektromagnet (Coil) dan Mekanikal (seperangkat Kontak Saklar/Switch). Rele menggunakan Prinsip Elektromagnetik untuk menggerakkan Kontak Saklar sehingga dengan arus listrik yang kecil, dapat menghantarkan listrik yang bertegangan lebih tinggi.

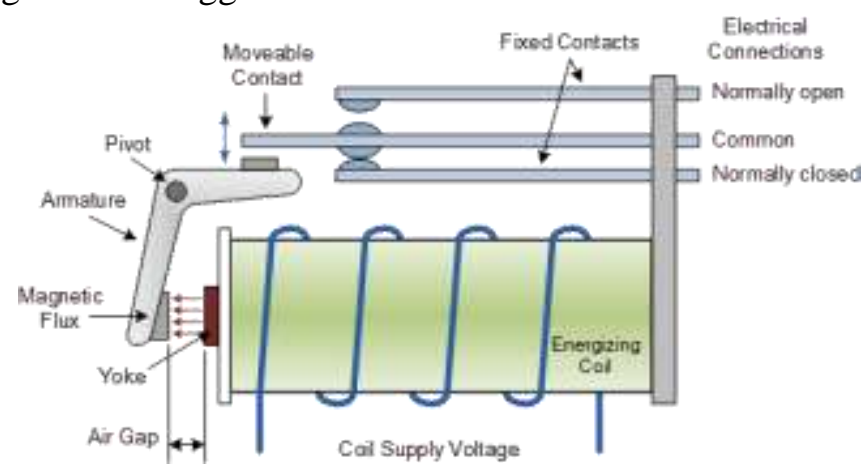

Gambar 3 Diagram Sebuah Rele [6]

Tegangan yang dibutuhkan rele cukup rendah, cukup 5 Volt saja. Dan untuk segmen C yang dibahas pada penelitian ini, kabel UTP bukan digunakan untuk catu daya, melainkan untuk menyalurkan logika 0 dan 1 , dimana logika logika 0 direpresentasikan dengan tegangan 0 s.d $1.35 \mathrm{~V}$ dan logika 1 direpresentasikan dengan tegangan $>3.15$ Volt [7].

\subsection{Harga Komponen}

Perbandingan harga pada penelitian ini tentu sangat bergantung pada harga komponen di pasaran lokal. Harga di tiap kota juga beragam, sehingga kesimpulan pada penelitian ini sangat bergantung pada asumsi harga yang ditentukan pada tiap komponen.

Pada penelitian ini, ada beberapa komponen yang harganya secara langsung mempengaruhi harga jaringan listrik, yaitu : kabel engkel, kabel LAN, modul Rele, terminal 1 lubang, dan Power Supply.

\section{PEMBAHASAN}

\subsection{Perancangan Prototype}

Dua prototype jaringan listrik sesuai dengan Gambar 1 dan Gambar 2 dibuat untuk menyimulasikan jaringan yang akan dianalisis. Satu prototype untuk jaringan konvensional dan satu prototype untuk jaringan berbasis rele.

Pada modul rele (Gambar 4), terdapat 3 pin ; VCC, GND, dan IN. Untuk mengontrol modul rele, Pin VCC dan GND dihubungkan dengan Power Supply, dan pin IN mengambil peran :

- Bila pin IN dihubungkan dengan GND, port COM dan NO (normally open) akan tertutup, dan port COM dan NC (normally close) akan terbuka [8].

- Bila pin IN tidak dihubungkan dengan pin manapun, port COM dan NO akan terbuka, sedang port COM dan NC akan tertutup [8]. 


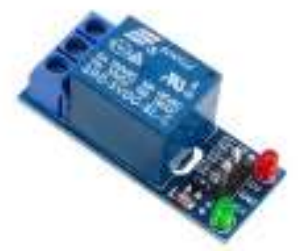

Gambar 4 Modul Rele [9]

Dari peran tersebut, maka saklar pada jaringan berbasis rele dihubungkan dengan pin GND dan pin IN sehingga bila saklar dalam keadaan tertutup (terhubung), modul rele juga dalam posisi tertutup. Dengan begitu, saklar "seolah" masih mempertahankan fungsinya sebagai pemutus dan penyambung arus listrik.

\subsection{Hasil Pengujian dan Pengukuran}

\subsubsection{Pengujian Prototype}

Hasil pengujian menunjukkan kedua prototype bekerja dengan baik. Kedua jenis jaringan menunjukkan kesamaan fungsi pada saklar. Saat saklar berada pada posisi OFF (terbuka), lampu tidak menyala. Dan saat saklar berada pada posisi ON (tertutup), lampu menyala. Kesamaan fungsi ini penting, terutama agar pengguna (user) mendapatkan pengalaman yang sama saat menggunakan jaringan konvensional dan jaringan berbasis rele.

\subsubsection{Pengujian Resistansi Kabel UTP}

Kabel UTP yang berukuran kecil memiliki hambatan yang cukup besar. Sehingga akan terdapat jarak maksimum, dimana kabel UTP tidak dapat lagi mengontrol modul rele. Pengujian Kabel UTP bertujuan untuk mengetahui besarnya redaman dari kabel UTP. Pengujian dilakukan dengan cara pengukuran secara langsung pada satu kawat kabel UTP dengan panjang kurang lebih 17 meter. Hasil pengukuran ditunjukkan pada Tabel 2. Sebagai catatan, angka yang ditunjukkan adalah redaman kabel ditambah dengan hambatan 2 buah jumper, dimana hambatan jumper kurang lebih $0.063 \mathrm{ohm}$.

Tabel 2 Hasil Pengukuran karakter resistansi pada kabel UTP

\begin{tabular}{|c|l|c|c|c|c|}
\hline $\begin{array}{c}\text { Pengukuran } \\
\text { ke }\end{array}$ & Hasil Ukur & $\begin{array}{c}\text { Pengukuran } \\
\text { ke }\end{array}$ & Hasil Ukur & $\begin{array}{c}\text { Pengukuran } \\
\text { ke }\end{array}$ & Hasil Ukur \\
\hline 1 & $4.497 \Omega$ & 8 & $4.460 \Omega$ & 15 & $4.497 \Omega$ \\
\hline 2 & $4.503 \Omega$ & 9 & $4.523 \Omega$ & 16 & $4.490 \Omega$ \\
\hline 3 & $4.519 \Omega$ & 10 & $4.577 \Omega$ & 17 & $4.476 \Omega$ \\
\hline 4 & $4.511 \Omega$ & 11 & $4.530 \Omega$ & 18 & $4.464 \Omega$ \\
\hline 5 & $4.612 \Omega$ & 12 & $4.514 \Omega$ & 19 & $4.481 \Omega$ \\
\hline 6 & $4.558 \Omega$ & 13 & $4.499 \Omega$ & 20 & $4.469 \Omega$ \\
\hline 7 & $4.444 \Omega$ & 14 & $4.505 \Omega$ & & \\
\hline
\end{tabular}

Dari tabel di atas, nilai redaman kabel didapat dengan mencari nilai rata-rata dari ke-20 data yang ada. Hasilnya, rata-rata tahanan kabel UTP adalah sebesar $0.262 \mathrm{ohm} /$ meter.

\subsubsection{Pengujian Drop Tegangan pada Kabel UTP}

Mengacu pada Subbab 3.2.2 tentang Pengujian Kabel UTP, pada panjang tertentu, akan terjadi drop tegangan. Kondisi tersebut akan terjadi pada panjang kabel tertentu, dimana nilai tersebut menjadi panjang maksimum kabel UTP yang dapat digunakan. Untuk menentukan 
panjang maksimum kabel UTP tersebut, kami membuat model. Untuk menggantikan kabel UTP, kami menggunakan resistor yang dirangkai seperti pada Gambar 5.

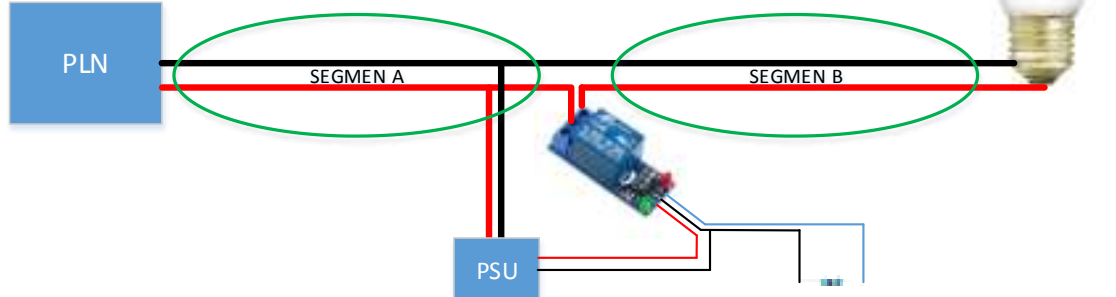

Gambar 5 Skema Pengukuran Batas resistansi pin IN dan GND

Tabel 3 Hasil Pengukuran Resistansi maksimum

\begin{tabular}{|l|l|l|}
\hline No & Besarnya Hambatan & Lampu Hijau Menyala \\
\hline 1 & $3.3 \mathrm{M} \mathrm{ohm}$ & Tidak \\
\hline 2 & $1.5 \mathrm{M} \mathrm{ohm}$ & Tidak \\
\hline 3 & $1 \mathrm{M}$ ohm & Tidak \\
\hline 4 & $12 \mathrm{k} \mathrm{ohm}$ & Ya \\
\hline 5 & $4.7 \mathrm{k} \mathrm{ohm}$ & ya \\
\hline
\end{tabular}

Tabel di atas menunjukkan bahwa redaman sebesar $12000 \mathrm{ohm}$ masih dapat ditolerir oleh modul rele. Jika dikonversi menjadi panjang kabel UTP sesuai hasil pengukuran pada subbab 3.2.2, maka panjang kabel UTP yang masih dapat ditolerir adalah 45800 meter. Karena segmen C membutuhkan 2 kawat, maka nilai tersebut harus dibagi 2 menjadi 22900 meter atau sekitar $23 \mathrm{~km}$.

\subsection{Analisis Perbandingan Harga}

Analisis perbandingan harga hanya dilakukan pada segmen $\mathrm{C}$, mengingat perbedaan mendasar dari kedua jenis jaringan yang diuji terdapat pada segmen $\mathrm{C}$.

Biaya yang dikeluarkan untuk jaringan konvensional hanya bergantung pada panjang kabel dan harga kabel yang digunakan. Sedang untuk jaringan berbasis rele, terdapat beberapa komponen, diantaranya : kabel UTP, modul Rele, stop kontak 1 lubang, dan Power Supply.

Power supply yang dibutuhkan tidak sebanyak jumlah rele, tetapi sesuai keperluan. Sebuah modul rele memerlukan catuan 5 Volt $71 \mathrm{~mA}$ (hasil pengukuran langsung). Sehingga power supply 5V 2A (charger ponsel) dapat mencatu hingga 28 modul rele

Bila diasumsikan :

$\mathrm{E}_{\mathrm{rp}}$ : harga kabel engkel (per 1 kawat per meter)

$\mathrm{T}_{\mathrm{rp}}$ : harga kabel UTP (per 1 kawat per meter)

$\mathrm{L}$ : panjang segmen $\mathrm{C}$

$\mathrm{S}_{\mathrm{rp}}$ : harga stop kontak 1 lubang

$\mathrm{N}$ : jumlah modul rele

$\mathrm{P}_{\mathrm{rp}}$ : harga power supply $5 \mathrm{~V} 2 \mathrm{~A}$

$\mathrm{R}_{\mathrm{rp}}$ : harga modul rele 1 channel

Maka harga jaringan konvensional (HJK) dan harga jaringan berbasis rele (HJR) adalah sebesar

$$
\begin{aligned}
& H J K=L \times 2 \times E_{r p} \\
& H J R=\left(L \times 2 \times T_{r p}\right)+\left(N \times R_{r p}\right)+(((N-1) \operatorname{div} 28)+1) \times\left(P_{r p}+S_{r p}\right)
\end{aligned}
$$

Div digunakan untuk memperoleh hasil Bulat dari operasi pembagian 
Dengan mengasumsikan harga Trp jauh lebih rendah dari harga Erp, $\mathrm{N}$ sudah dapat ditentukan dari awal, dan semua harga komponen sudah diketahui, maka contoh perbandingan harga HJK dan HJR dapat digambarkan seperti grafik berikut :

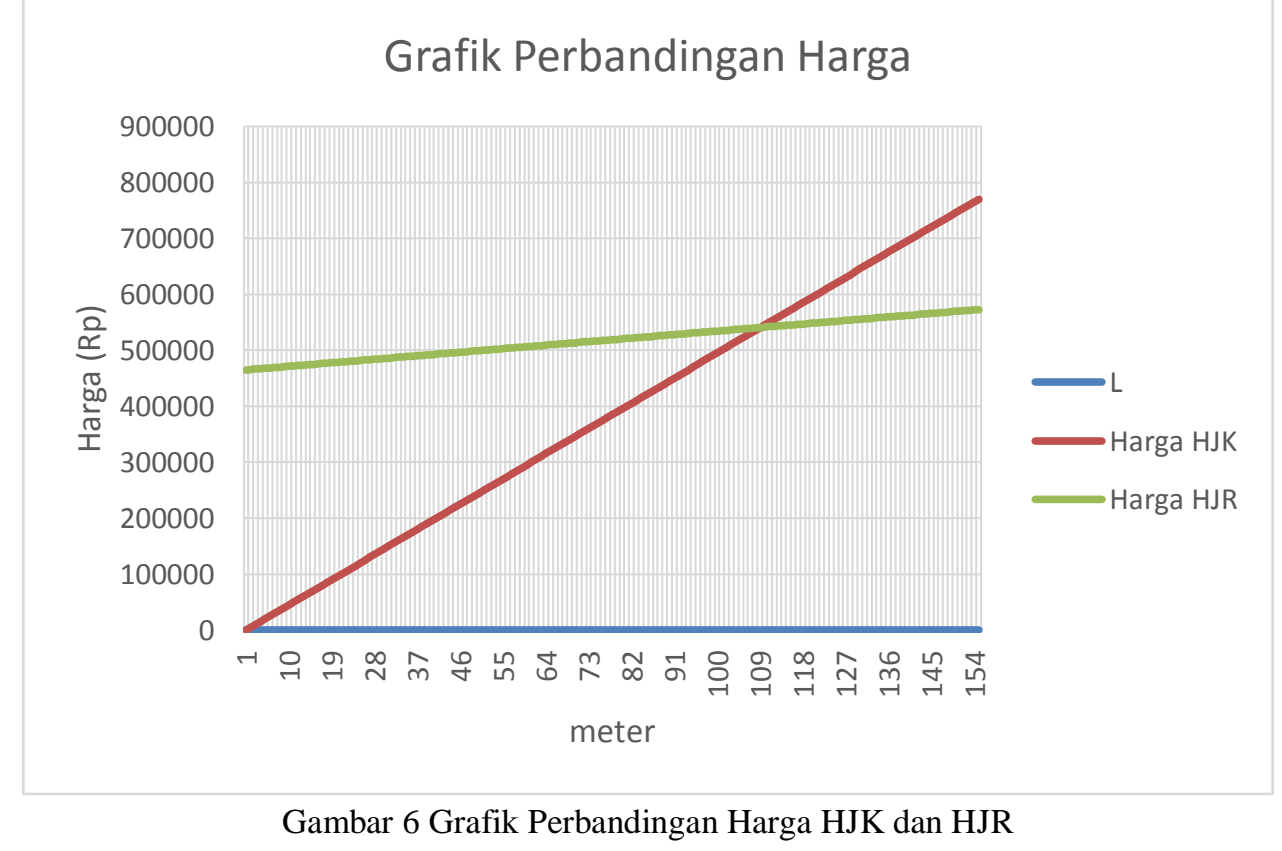

Titik temu kedua grafik (hijau dan merah) adalah titik pada L tertentu dimana HJK dan HJR memiliki nilai yang sama. Nilai $L$ tersebut dapat dicari dengan persamaan :

$L=\frac{\left(N \times R_{r p}\right)+(((N-1) d i v 28)+1) \times\left(P_{r p}+S_{r p}\right)}{\left(2 \times E_{r p}-2 \times T_{r p}\right)}$

Bila panjang segmen $\mathrm{C}$ lebih besar dari L, maka Jaringan berbasis rele lebih murah dibandingkan dengan jaringan konvensional. Sedang jika panjang segmen $\mathrm{C}$ lebih rendah dari $\mathrm{L}$, Jaringan konvensional lebih murah daripada jaringan berbasis rele.

\section{KESIMPULAN DAN SARAN}

\subsection{Kesimpulan}

1. Prototype jaringan berbasis rele bekerja dengan baik. Saat menggunakan jaringan berbasis rele, user merasakan pengalaman yang sama dengan saat menggunakan jaringan konvensional.

2. Kabel UTP memiliki hambatan $0.262 \mathrm{ohm}$ per meter.

3. Segmen C pada jaringan berbasis rele, dapat mencapai jarak 22900 meter atau 22.9 $\mathrm{km}$. Dengan nilai ini, jaringan berbasis rele ini layak digunakan untuk gedung berukuran besar.

4. Biaya yang dibutuhkan untuk jaringan konvensional sama dengan biaya yang dibutuhkan untuk jaringan berbasis rele untuk panjang segmen $\mathrm{C}=$ $L=\frac{\left(N \times R_{r p}\right)+(((N-1) \operatorname{div} 28)+1) \times\left(P_{r p}+S_{r p}\right)}{\left(2 \times E_{r p}-2 \times T_{r p}\right)}$

5. Bila panjang segmen $\mathrm{C}$ lebih kecil dari $\mathrm{L}$, harga jaringan konvensional lebih rendah daripada jaringan berbasis rele

6. Bila panjang segmen $\mathrm{C}$ lebih besar dari $\mathrm{L}$, harga jaringan berbasis rele lebih rendah daripada jaringan konvensional. 


\subsection{Saran}

Tabel 3 (pengukuran resistansi maksimum) belum sempurna, karena terdapat gap yang cukup jauh antara $12 \mathrm{k} \mathrm{ohm}$ dan $1 \mathrm{M} \mathrm{ohm}$. Hal ini karena keterbatasan resistor untuk diujicobakan di laboratorium. Pengukuran yang lebih presisi terhadap resistansi pada gap tersebut diharapkan mampu memperbaiki kesimpulan awal yang menyatakan bahwa jarak maksimum segmen $\mathrm{C}$ adalah 22900 meter.

\section{DAFTAR PUSTAKA}

[1] Bahriun, T. Ahri. 2005. Rele Tegangan Elektronik. Fakultas Teknik, Universitas Sumatera Utara.

[2] Charles K. Alexander, dan Matthew N.O. Sadiku. 2009. Fundamentals of Electric Circuits $4^{\text {th }}$ edition. New York : McGraw-Hill Companies inc.

[3] Penjelasan PUIL (Persyaratan Umum Instalasi Listrik). 2011. Kementerian Energi dan Sumber Daya Mineral.

[4] [Online] Tersedia di www.siemon.com/share/products05/cable_solution6-plenumus_oil.jpg [diakses pada 2 Januari 2018].

[5] Wicaksono, Handy. 2009. Relay - Prinsip dan Aplikasi. Catatan Kuliah "Automasi 1" : Universitas Kristen Petra

[6] Relays. [Online] Tersedia di https://www.letscontrolit.com/wiki/index.php/Relays [diakses pada 29 November 2017].

[7] Datasheet. SN74HC04. Texas Instrument.

[8] Robinzon Pakpahan, Dadan Nur Ramadan, dan Sugondo Hadiyoso. 2016. Rancang Bangun dan Implementasi Automatic Transfer Switch (ATS) Menggunakan Arduino Uno dan Relai. Jurnal Elektro Telekomunikasi Terapan Vol. 3 No. 2 Desember, 332 - 341.

[9] 1 Channel Relay Module (Active Low Control). [Online] Tersedia di https://www.addicore.com/Single-Channel-Relay-Module-p/ad317.htm [diakses pada 29 November 2017]. 